\title{
Implementing Health-Promoting Leadership in Municipal Organizations: Managers' Experiences with a Leadership Program
}

I Robert Larsson'

Doctoral student, School of Health, Care and Social Welfare, Mälardalen University, Sweden

I Jonas Stier

Professor, School of Health, Care and Social Welfare, Mälardalen University, Sweden

\section{Ingemar Åkerlind}

Professor Emeritus, School of Health, Care and Social Welfare, Mälardalen University, Sweden

\section{Hélène Sandmark}

Associate Professor, School of Health, Care and Social Welfare, Mälardalen University, Sweden

\begin{abstract}
The aim of this study was to analyze how line and middle managers experience and describe barriers and enablers in the implementation of a health-promoting leadership program in municipal organizations. A qualitative case study design was applied to examine the leadership program in a case involving implementation of an organizational health intervention. Data were mainly collected using semi-structured interviews with line and middle managers participating in the leadership program. Interviews with senior managers, notes from meetings/workshops, and written action plans were used as complementary data. The interview data were analyzed using a thematic analysis, and the complementary data using a summative content analysis. The findings show that the interviewed line and middle managers experienced this leadership program as a new approach in leadership training because it is based primarily on employee participation. Involvement and commitment of the employees was considered a crucial enabler in the implementation of the leadership program. Other enablers identified include action plans with specific goals, earlier experiences of organizational change, and integration of the program content into regular routines and structures. The line and middle managers described several barriers in the implementation process, and they described various organizational conditions, such as high workload, lack of senior management support, politically initiated projects, and organizational change, as challenges that limited the opportunities to be drivers of change. Taken together, these barriers interfered with the leadership program and its implementation. The study contributes to the understanding of how organizational-level health interventions are implemented in public sector workplaces.
\end{abstract}

\section{KEY WORDS}

Health promotion / Implementation / Intervention / Leadership / Line and middle managers / Municipality / Organizational level / Sweden / Workplace health

\footnotetext{
${ }^{1}$ Robert Larsson, School of Health, Care and Social Welfare, Mälardalen University, Box 883, SE 72123

Västerås, Sweden. E-mail: robert.larsson@mdh.se
} 


\section{Introduction}

$\mathrm{n}$ recent years, there has been an increasing focus on the importance of organizational factors in occupational health research (Härenstam et al., 2006). In line with this, other approaches, complementary to traditional occupational health and safety (OHS) initiatives, have been developed. One such complementary approach is workplace health promotion (WHP). Given the amount of time employees spend at work, the workplace is seen as an important setting for health promotion (Chu et al., 2000). The setting-based approach to WHP considers the influence that the workplace itself has on employee health. Although WHP lacks an agreed-upon definition, in Europe it has been broadly defined as 'the combined effort of employees, employers and the community to improve the health and wellbeing of people at work' (European Network for Workplace Health Promotion, 2007, p. 2).

Traditionally, many employers promote employee health by providing employees with various health behavioral interventions while other organizations have developed allembracing strategies to improve employee health. The WHP approach, however, emphasizes a comprehensive approach combining individual- and organizational-directed interventions (e.g., Shain and Kramer, 2004). This broader view is also underlined in contemporary conceptualizations of WHP, addressing both the design of the work organization and the work environment, although not abandoning the promotion of personal development and health practices (European Network for Workplace Health Promotion, 2007). Thus, WHP adheres to a holistic understanding of health, emphasizing the interplay of individual, organizational, and environmental factors as health determinants (Stokols et al., 1996). Health promotion also views health as a resource in people's everyday life, usually defined as the 'process of enabling people to increase control over and to improve their health' (World Health Organization, 1986, p. 1). Consequently, this comprehensive approach to WHP also implies a broader empirical scope.

Following the shift in occupational health research toward organizational factors and their influence on employee health, a renewed interest in organizational-level interventions aiming to improve psychosocial working conditions and employee health has been noted (Nielsen et al., 2010). Similarly, leadership research, which has developed as a specific line of research, has in recent years been linked more closely to organizational health interventions. There is also some support for the effectiveness of leadership interventions on employee health (Kelloway and Barling, 2010). In this context, the concept of health-promoting leadership has been launched, gaining the most attention in the Nordic countries. Although the concept lacks a clear definition, it has been described as reflecting a Scandinavian leadership tradition, including a process-oriented and participatory view on leadership (Eriksson, 2011). However, empirically, it has been described as organizational actors (e.g., managers) tending to give different meanings to health-promoting leadership, varying from the organizing of healthy lifestyle activities to the managerial responsibilities involved in developing a healthy work environment (Eriksson et al., 2010).

In general, it is not a given that leadership programs should be viewed as organizational health interventions (Kelloway and Barling, 2010). However, when leadership programs involve a participatory approach and focus on social exchange processes between managers and employees, and not only the individual leader, then they can be viewed as organizational-level interventions with the potential to enhance employee 
health. Furthermore, it has been argued that this type of organizational health intervention can be compared with the implementation of other planned organizational changes, albeit often with a less pronounced economic perspective (e.g., KaranikaMurray and Biron, 2013). In addition, Weiner et al. (2009) argue for an organizational perspective in research on implementation of WHP interventions due to their involvement of organizational actors, collective use, and inherently authoritative elements. Meanwhile, reviews of organizational health interventions indicate that few studies have investigated the implementation of this kind of interventions (e.g., Egan et al., 2009). Moreover, research on organizational health interventions ought to give more attention to the role of line and middle managers when organizational health interventions are implemented.

To summarize thus far, few studies have investigated the implementation of healthpromoting leadership programs, and to our knowledge, no one has studied such a program by adopting organizational change theory (cf., Eriksson et al., 2010). Therefore, there is a need for in-depth knowledge of how such a leadership program is implemented within a public sector context. This could also be of interest given the complexity involved in politically governed organizations, as well as a changed institutional logic influenced by management ideas emphasizing marketization in municipalities and similar human service organizations (Hasenfeld, 2010). Thus, the aim of this study was to analyze how line and middle managers experience and describe barriers and enablers in the implementation of a health-promoting leadership program in municipal organizations. By doing this, the study aims to contribute with knowledge concerning how particular organizational actors, in this case, line and middle managers, view and experience the implementation of an organizational health intervention.

\section{Previous research on organizational health interventions}

In previous research, organizational health interventions have been referred to as interventions conducted in the workplace to change the way work is organized, designed, and managed (Nielsen, 2013). As such, they focus on changing the social, structural, and political aspects of the organization, and evaluation of such organizational health interventions has proven to be a complex task (Biron et al., 2012). While individual-directed interventions addressing various health behaviors produce relatively consistent positive health outcomes (e.g., Goldgruber and Ahrens, 2010; Sockoll et al., 2009), evidence for organizational-level interventions on employee health is weaker and inconsistent (Montano et al., 2014; Sockoll et al., 2009). This is the case although organizational health interventions are assumed to produce more sustainable results because they focus on upstream factors, such as work organization design and leadership practices, which are of importance for employee health (LaMontagne et al., 2007). A future challenge is thus to understand these inconsistent results, and lately several scholars have highlighted a need for studies addressing process and contextual issues (Biron et al., 2012; Cox et al., 2007; Nielsen and Abildgaard, 2013; Nielsen and Randell, 2013).

It has been suggested that organizational health interventions usually fail, not because of problems in content or overall design, but because of poor implementation (Biron et al., 2012). In previous research, the term 'process evaluation' is used for studies analyzing how and why health interventions succeed or fail in bringing about 
intended effects (Linnan and Steckler, 2002). Process evaluation is often described with the metaphor of the 'black box' that needs to be opened to attain adequate information on process-related and contextual issues influencing the intervention and its outcomes (Linnan and Steckler, 2002). Research on organizational health interventions shows that few studies have taken an interest in how and why interventions work (or do not work), and systematic reviews indicate that 'process-relevant' factors usually are poorly described in these studies (Egan et al., 2009; Murta et al., 2007). This lack of information makes it difficult to fully explain the implementation as well as to consider issues relevant to process and context when planning for future implementation of organizational health interventions (Montano et al., 2014).

Although 'process studies' of organizational health interventions are limited, there are those which point to several influential factors affecting successful implementation of interventions. For instance, management support and employee participation are recurrent issues reported to affect the implementation of organizational health interventions (Nielsen et al., 2006; Nytrø et al., 2000; Saksvik et al., 2002). Other empirical studies indicate that social climate (Nytrø et al., 2000), unclear roles and responsibilities (Nielsen et al., 2006; Saksvik et al., 2002), and competing projects and reorganization (Saksvik et al., 2002) influence the implementation of interventions. A recently conducted process study within the frame of a leadership intervention aiming to investigate and develop organizational conditions for municipal managers reveals nine factors that promote the implementation of the intervention. Among these factors are process support, broad ownership, and support from local project staff. In addition, this study also illustrates how contextual factors such as changes due to political elections influence the implementation (Lindgren, 2014). Further research is needed, however, as organizational health interventions involve many people, multi-component programs, and complex processes that require investigation by studies not limited to the effects of the intervention.

\section{The role of line and middle managers in organizational health interventions}

Senior managers often make formal decisions on organizational change and interventions, whereas line and middle managers are usually responsible for communicating and implementing change (Nielsen and Randell, 2013). In addition, line and middle managers are expected to be active participants and sometimes explicate 'targets' for change in organizational health interventions. Hence, they are co-creators involved in determining how and why interventions work (Nielsen, 2013), and they therefore play an important role and are in a position to hinder or facilitate change (Nielsen and Randell, 2013). This is further supported by studies indicating that middle managers can oppose change (Saksvik et al., 2002) as well as be drivers of change, involving and motivating employees to engage in organizational health interventions (Hasson et al., 2014). Also of importance are managers' concrete handling of intervention activities (Nielsen and Abildgaard, 2013) as well as micro-politics and conflicts related to organizational change (Dawson, 2003). Consequently, managers can either reinforce or impair the conditions for organizational health interventions; this justifies studies analyzing their experiences. 


\section{Theoretical approach}

In this study, our point of departure lies within the field of health promotion, and we draw on a comprehensive understanding of WHP (European Network for Workplace Health Promotion, 2007; Shain and Kramer, 2004). Furthermore, we included recent organizational psychology research addressing process-related and contextual issues related to organizational health interventions (Biron et al., 2012; Nielsen and Abildgaard, 2013; Nielsen and Randell, 2013). Because of this, our study lies at the intersection of these two adjacent and partially overlapping research fields. However, both these fields have been noted as being theoretically weak in relation to processes and contextual issues influencing the implementation of organizational health interventions (KaranikaMurray and Biron, 2013; Weiner et al., 2009).

Given this theoretical weakness, researchers have argued for a view of organizational health interventions as representing a particular case of organizational change (Karanika-Murray and Biron, 2013; Tetrick et al., 2012). Likewise, similar reasoning is applied in the WHP literature, often in the form of a step-by-step approach to the implementation of planned health-related change (O'Donnell, 2002). Thus, much of this literature reflects Lewin's influential unfreeze-change-refreeze model of organizational development (Lewin, 1951). Although this perspective to organizational change has been influential, recent discourses have criticized such a rationalistic approach for its simplified view on organizational change and inadequate accounting of processes and contextual issues (see Caldwell, 2005). From a processual (contextual) perspective, it has, therefore, been argued that such aspects need to be considered in organizational change research (Pettigrew, 1997).

As this study focuses on the implementation of an organizational health intervention (i.e., leadership program), we draw on this processual and contextual thinking about organizational change when analyzing the program implementation. The fundamentals of the processual perspective are the concepts of process, content, and context (Pettigrew, 1997). According to Burke (2011) the content of change is related to the direction of the change, while the process refers to how change is implemented. Additionally, the context is related to the where, when, who of the change (Burke, 2011). More specifically, the process has been referred to as 'a sequence of individual and collective events, actions, and activities unfolding over time in context' (Pettigrew, 1997, p. 338). Similarly, more refined definitions of context have been proposed. Johns (2006) suggests the distinction between omnibus context, which refers to the broader context, and discrete context, referring to more specific contextual issues influencing behaviors or attitudes. Here, it is also important to point out the reciprocity between organizational actors and context, meaning that context is both shaping and shaped (Pettigrew, 1997). Moreover, this processual perspective on organizational change involves the politics of change, meaning conflicts arising between different organizational actors (Dawson, 2003). Applied to the implementation of organizational health interventions, this perspective means that the implementation needs to be understood as a collective endeavor involving different organizational actors, as well as a set of change activities interacting or competing with a line of concurrent events (Nielsen and Abildgaard, 2013). These complex interventions also need to be adapted to existing work practices and contextual conditions. These latter process-related and contextual aspects are also reflected in the definition of implementation that we follow in this study: 'all real actions taken to implement the intervention, being 
best understood as an interaction (or even co-production) between the actors implementing the intervention and the target system' (Bauer and Jenny, 2013, p. 10).

\section{The leadership program}

We used a leadership program that focuses on rewarding and sustainable healthpromoting leadership as a case study of an organizational health intervention. The leadership program is theory-driven, drawing on theories of transformational leadership (Bass and Riggio, 2006) and a framework for the relationship between leadership and employee health provided by the Job Demands-Resources Model (Bakker and Demerouti, 2007). The program involves training real-life behaviors and does not rely only on lecture-related knowledge. Hence, the intention of the program is to change leaders' behaviors into more rewarding and health-promoting practices and to determine whether on-the-job leadership training has the potential to improve leaders' behaviors and positively affect employees' psychological well-being and health. Furthermore, the program is extended over a longer time, instead of teaching sessions conducted over a few intensive work days, and is planned for work groups no larger than 15 employees for each leader (hereinafter, these leaders are called 'managers' as they have formal managerial responsibilities; Yukl, 2006).

The leadership program is organized into modules (e.g., theory, goal-setting, evaluation with feedback) and covers a period of 13-15 months. A broad range of intervention activities is offered to managers (i.e., leader workshops, coaching, diary writing, team climate observations) and to employees (i.e., lectures, observations, team workshops). A core component of the program is the team workshop, in which the researchers present the results from the baseline measurement (i.e., first wave) using a survey-feedback method. Thereafter, the employees discuss the results and develop an action plan for the program, including goals, target areas, and responsibilities. Overall, the project research team (i.e., other than the authors) initiated and conducted activities and thus had roles as lecturers, workshop coordinators, observers, and coaches (for a more detailed presentation of the design, content, and outcomes of the leadership program, see Rigotti et al., 2014).

\section{Methods}

\section{Research design}

This study uses a qualitative, holistic single-case study design, in which the health-promoting leadership program is viewed as the 'case' to be described and analyzed (Yin, 2009). The case study design was chosen because it is suitable when studying complex processes in their natural context and because the leadership program represents a case of implementing an organizational health intervention (Yin, 2009).

Although this case study is limited to the collection of qualitative data, the leadership program was also followed longitudinally using a quasi-experimental design, including three waves of measurement of both individual and organizational outcomes (see Rigotti et al., 2014). In total, 18 line and middle managers and their employees 
( $\mathrm{n}=259)$ from two municipal organizations participated from the start of the program. In this case study, we do not include the employees' views on the implementation process or the program's effectiveness in terms of leadership and health outcomes.

\section{Organizational settings}

The leadership program was implemented in two Swedish municipalities, each with around 100,000 inhabitants, and located in the wider Stockholm-Mälardalen region. In Sweden, municipalities are self-governing local government organizations responsible for providing welfare services for citizens who reside therein. As such, they are themselves large employers. The organizations included in this study have together approximately 19,000 employees, and both organizations are mostly female-dominated workplaces.

\section{Participants and data collection}

Data were collected using semi-structured interviews with managers who participated in the leadership program as well as with senior managers. The participating managers held line and middle manager positions, and they had voluntarily signed up for participation in the leadership program. All managers $(n=17$; one of the managers dropped out at an early stage) were invited for interviews, and 11 of these chose to participate. Of the interviewed line and middle managers, eight were women and three men, and their ages ranged between 35 and 62 years. The interviewed managers represented a variety of municipal services such as pre-school, elementary school, elderly care, social service, property management, and urban planning. The leadership program was planned for work groups of 15 employees, but the actual work groups had between 5 and 23 employees. The work groups were in most cases part of larger units that varied between 5 and 42 employees. In addition, five senior managers not actively participating in the leadership program were interviewed. The purpose of these interviews was to gain insight into how the leadership program was seen and communicated with senior management.

All interviews were conducted individually, face-to-face, using a thematic interview guide with open-ended questions (Kvale and Brinkmann, 2009; Patton, 2002). The themes concerned program content, implementation, and effects. Questions were also asked about contextual issues: work organization, organizational change, and conditions for WHP. The interviews with senior managers concerned the general management of WHP at the department level. These interviews focused on organization and leadership strategies, as well as health promotion and work environment. During the interviews, probing questions were used encouraging the interviewees to elaborate and clarify their responses (Patton, 2002). All interviews were conducted by the first author (RL), lasted between 28 and 60 minutes (average: 40 minutes), and were audio-recorded.

In addition to collecting interview data, one of us (RL) participated in program meetings/workshops. On average, these meetings/workshops lasted for two hours, and notes from six such occasions were used in the analysis. Further, the program action plans were collected and used as complementary data (Yin, 2009). 


\section{Analysis}

The interviews were transcribed and analyzed using a theoretical thematic analysis (Braun and Clarke, 2006), guided by a processual framework (Dawson, 2003). In general, the processual perspective is concerned with how people (in this case, the line and middle managers) experience the 'change process' (i.e., intervention). As a first step, we used the framework for locating and sorting the complex change data systematically, whereupon it was used for thematic analysis. The processual framework covers three broad areas and is concerned with understanding the substance of change, considering scale and type of change including barriers and enabling characteristics of change; the context of change, referring to internal and external conditions for the organization in which change occurs; and the politics of change, involving organizational politics and micro-politics of change (e.g., resistance).

Specifically, the transcribed interviews were read and re-read as a way of familiarizing with the data. Thereafter, initial codes were generated, and the codes were sorted into potential themes guided by the analytical framework. Finally, the themes were reviewed in relation to all codes previously generated. The analysis was initially conducted by the first author (RL) and subsequently discussed with the co-authors to ensure credibility, and by this process, themes were further clarified and refined. A complementary review of action plans was conducted to contextualize the interview data, which involved skimming and closer reading (i.e., review) of the documents (Bowen, 2009). The action plans were then analyzed using a summative content analysis. In total, 18 documents were included in the analysis.

\section{Ethical aspects}

We conformed to research ethics by informing the participants about the study aims and by obtaining verbal and written informed consent for the interviews. The participants were also informed about confidentiality and their right to withdraw at any time from the interviews. Participants were asked for permission to audio-record the interviews. This study was approved by the Regional Ethical Review Board in Uppsala, Sweden (Dnr: 2012/183).

\section{Findings}

Two main themes emerge from the interviews: renewal of leadership training and $d y$ namics and politics of change in the municipal organizational context. These themes and related subthemes illustrate barriers and enablers experienced by the line and middle managers regarding the implementation of a health-promoting leadership program at municipal workplaces.

\section{Renewal of leadership training}

The leadership program is described by the interviewees as a renewed way of conducting leadership training because it includes program characteristics emphasizing employee 
involvement. Process issues are identified by the line and middle managers as either enabling or hindering the implementation of the leadership program and related action plans. Although the program is seen as a new way of conducting leadership training, the interviewees have difficulty identifying effects and describing new work practices emanating from the leadership program.

\section{Mixing new and old program features}

The interviews show that the line and middle managers experience this particular healthpromoting leadership program as different from their earlier experiences of leadership training. They depict their earlier leadership training as more focused on the individual leader's thinking and behavior, while this leadership program at an early stage involved their employees. This focus on employee participation is stated as a reason why the managers were interested in participating in the program. In particular, they emphasize the social interaction between the manager and the employees.

It wasn't just a focus on the managers, but also quite a lot of focus on employees and interactions. I thought it felt rather new and useful.

The leadership program had a broad range of activities stretching over a longer period. According to the interviewees, program activities did not fit all of them, and they describe participation in the program activities as depending on their own curiosity, individual preferences, and earlier experiences. They report diary writing and coaching were the two least utilized and least interesting activities by managers. None of the interviewees completed the full diary-writing process, and they say it was due to lack of time. The reasons they give for not participating in the coaching session are either that they already have a coach/mentor or that they have been coached before, and found that it did not suit them.

I haven't been involved in all elements. I participated in the first diary writing but not in the second one. I simply had no time to devote myself to it.

At the same time, the managers refer to this program as containing fewer practical exercises compared with their previous experience of leadership training.

\section{Action plans as means to put the program into practice and make things happen}

Given the program's focus on employee involvement, the interviewees view the team workshop and the development of the action plan as a key element and the most useful and well-functioning activity in the leadership program.

The workshop that's where ... making concrete plans of action, that's the real value.

Through an initial risk assessment and survey feedback, reporting on psychosocial working conditions in each work group, the managers describe various ways of how 
they chose to organize and manage the work related to the action plan. The interviewees explain that they dealt with the action plans at workplace meetings but also on special days for planning and competence development. However, not all of the managers describe such structured work on the action plans, with some describing instead an ad hoc way of working. The managers include as enablers having an action plan with specified goals, as well as their work group's commitment to the implementation of change. As other enablers, they emphasize earlier experiences of organizational change among the employees as well as the importance of integrating the action plans with already existing plans (e.g., work environmental plans) and regular work practices.

It was really a natural part of the work we already do, and it felt good, I think. You shouldn't just come up with a lot of things so it becomes a kind of fiction, but instead we're going to do this anyway. We evaluated the action plan and we've done a lot of it.

The interviewees mention a number of barriers to the implementation of the action plans. They describe how many employees lack experience of organizational change because this is usually given little attention in everyday work. This lack of experience is also manifested in the employees' struggle to formulate specific goals in the action plans. Furthermore, this inexperience is described as a double challenge for employees, both learning how to implement the change process and how to apply it to workplace health issues.

This was the first time that my work group had been working with action plans for real. So there were a lot of goals that were very unclear and unmeasurable and so on. And what I felt when we started to work on the next action plan, which we have now done, was that it became clearer at once. It gets better and better every time ...

Managers also refer to initial resistance among employees to participating in action planning and the subsequent work related to the program. However, this resistance is described as an initial barrier not uncommon for similar types of change processes, and it is talked about as being possible to overcome.

\section{Difficulties capturing the 'effects'}

The overall picture that emerges from the interviews is that the line and middle managers themselves are reluctant to identify any effects of the leadership program. The interviewees explain that the program intensity, meaning both the amount of and the time between program activities, is insufficient to demonstrate or experience any effects. The managers stress that the leadership program lasted a long time, and therefore it may be difficult to sort out its effects in relation to other concurrent organizational changes.

What you may need to consider in a project this lengthy is that there is so much going on in working life in the meantime. And an organization like ours works a lot with goals, actions, activities, and follow-up, so things happen. [...] And then it can be a little difficult to determine what the benefits of the project were and what would have happened anyway. 
Another difficulty raised by the interviewees as to why it may be difficult to identify any effects is that many goals in the action plans focus on 'soft domains' such as cooperation, communication, trust, feedback, and participation. Paradoxically, they nonetheless describe experiences of improved communication, cooperation, and trust, both among employees in their work group and in relation to themselves. The managers believe that they only made small changes in their leadership behavior, such as asking a second time or listening more attentively.

The goals and action plan were of such a nature that there was nothing that could be ... Communication is nothing that you improve in six months or a year; it takes several years of work, I think. It involves years of effort to increase the maturity among the employees. Noting that you have your own responsibility, both to develop [yourself] and to develop others.

\section{Dynamics and politics of change in the municipal organizational context}

The interviewees depict the organizational context as dynamic and characterized by competing projects, initiatives, and restructuring processes. Moreover, they describe varying organizational conditions reflected in varied workload, resources, and decisionmaking authority, which, in turn, constitute either barriers or enablers in the implementation of the leadership program. The implementation process is also described as being affected by relations with their senior management and by political decisions and initiatives.

\section{Organizational conditions matter}

As the line and middle managers represent different municipal domains, they depict varied organizational conditions as influencing the implementation of the leadership program. They describe this as being related to the type of municipal domain in which they operate, resulting in different workloads and resources either limiting or providing opportunities to be involved in the implementation process. For example, managers in schools and elderly care describe having larger work units as well as being responsible for more employees compared to managers in urban planning and property management. In particular, a high workload and, therefore, a lack of time for their employees is a challenge to overcome in terms of the implementation of the action plan and being a driver of change. The managers emphasize meetings, recruitment, and individual staff issues as mainly contributing to the heavy workload.

Yes, what's happening in the organization, it's ... Yes, it has really affected my opportunity to work with health-promoting leadership. All these meetings that we've had, all of these demands and messages of change ...

There are also feelings of guilt about the inability to fully engage in the program implementation. The managers express that they tried to give high priority to this program in spite of a generally high workload. 
As part of the dynamic context, the managers refer to several other competing projects and initiatives being carried out while implementing the leadership program. These initiatives included both new projects and new routines in the form of implementation of various administrative, economic, and information technology systems. Projects and implementation of new routines and administrative and budget systems are described as needing to be given higher priority because these are more clearly a part of the everyday job. Therefore, these projects and initiatives are described as time-consuming and as 'stealing' time, thereby affecting the managers' ability to engage in the leadership program.

Especially this second half year, we've had so many projects going on at the same time, economic projects and organizational projects that've involved the line organization. It may not be unique for the property management office that there's things going on in parallel ...

Initiatives facilitating and strengthening the commitment to the leadership program are also mentioned by the managers. The clearest example of this is the implementation of an earlier leadership development program intended for all managers in one of the municipal organizations. According to interviewees participating in both programs, the content of the health-promoting program is complemented by the municipality's own leadership program since this program does not involve the employees, but rather aims to strengthen the individual capability of the leader (e.g., communication skills) by providing practical tools.

There was a lot more training in 'Courageous leadership' [i.e., the municipality's own leadership program] that I could then use in health-promoting leadership.

In the interviews, the line and middle managers also refer to organizational restructuring as affecting the implementation of the investigated leadership program. Both small mergers of work groups as well as more extensive restructuring processes (e.g., splitting of departments and larger work units) are described. The more extensive restructuring processes meant that the program implementation had to be downplayed on the participating managers' agenda, and in some cases, the restructuring process also meant a change of staff at the senior management level. Conversely, the smaller mergers of work groups are experienced as not having influenced the implementation process significantly.

\section{Relation to and influence of upper-level stakeholders}

In the interviews, the line and middle managers describe the relation to their own senior management and how this affects the implementation of the present leadership program. Their relationship is described as relatively weak or completely absent. Consequently, there are interviewees who viewed this lack of interest and support from senior management as challenging because it means that senior management does not actively support change. Some initial communication with senior management is mentioned but is described as gradually decreasing over the duration of the program. 
At the beginning, there was some dialogue with the upper-level management, who thought this was good, and we were discussing it. But then, there hasn't been any direct support from my own department and no follow-up ...

This experience of lacking senior management support is not entirely uniform among the interviewees, and not all experienced this lack of interest and support or even the need for such support. This variation is also confirmed in the interviews with senior managers, where some describe encouraging their participating managers to share experiences from the program with other line and middle managers. The senior managers also reported getting initial information from the project researchers but less communication during the program implementation itself.

The interviewees depict consequences of working as a manager in a politically governed organization where the politicians, for example, come up with decisions and projects at short notice. These kinds of political initiatives are described as being part of everyday work within a municipality, and they jeopardize the ability to implement the leadership program by being time-consuming and contributing to a high workload.

And then in May this year it was decided by the politicians that now the schools shouldn't be part of the provider organization anymore but are put outside and placed [directly] under the politicians, so to speak. [This is] starting in January, and it has been an incredibly strange journey ...

Additionally, the interviewees describe how they, as individual managers, or their employees could end up in conflicts as a result of political proposals or decisions. If so, the managers describe it as taking much energy and influencing their ability to drive change in initiatives such as the present leadership program.

Sometimes in the political world, employees can feel a bit squashed because you end up in the political firing line and have the issue of how to handle yourself in these situations and how to cope when you, as an innocent expert get the blame for something. It's the kind of thing that sometimes happens in our world ...

\section{Content of the action plans}

A review of the action plans shows that cooperation, communication, and high workload are among the most common target areas to be addressed in the action plans. Other frequent areas concern fitness and well-being, feedback, role clarity, group dynamics, and reduction of group conflicts. Less common target areas are questions concerning sickness absence, organizational structure, and acquiring new competencies. Accordingly, the action plans largely covered target areas related to the psychosocial work environment but also more health-specific areas related to fitness and general well-being among employees. The picture that the line and middle managers conveyed regarding the lack of specific, realistic, and measurable goals is also confirmed by the content of the action plans. 


\section{Discussion}

The aim of this study was to shed light on barriers and enablers experienced by line and middle managers involved in the implementation of a health-promoting leadership program. The findings indicate that the managers are positive regarding the main content of the leadership program, and they highlighted the focus on employee involvement as a new and interesting approach to leadership training. The timeframe of the program is a challenge as the managers are not used to leadership training being so lengthy and timeconsuming. They saw the program as competing with day-to-day work tasks, making it difficult to maintain activities related to the program action plan. The findings indicate varying organizational conditions for managers in their respective departments, with managers describing a generally high workload and often inadequate or nonexistent support from senior managers, making it hard to drive change. Moreover, the managers operated within dynamic organizations characterized by organizational change, with difficulty finding time for things beyond the everyday managerial work. Working within politically governed organizations means that the line and middle managers, and ultimately the implementation of the leadership program, are influenced by sudden political decisions and initiatives that come before other changes. In the discussion below, the findings from this study are discussed in relation to previous research and the processual framework used for the analysis.

The leadership program involved an 'on-the-job training' approach, with the twofold purpose of developing health-promoting leader capabilities emphasizing employee involvement and promotion of the psychosocial work environment as a whole. In terms of the content of the leadership program (change), we found that line and middle managers view employee involvement in team workshops and subsequent work with the action plans as a key component. Placing such value on participation corresponds both to previous research on organizational health interventions and WHP theory (European Network for Workplace Health Promotion, 2007; Karanika-Murray et al., 2012; LaMontagne et al., 2012; Nielsen et al., 2010). Our findings indicate that the employees were involved in the program, although everyday work sometimes limited participation in certain intervention activities. Inauen et al. (2012) argue that employee participation can be viewed both in terms of breadth and depth, and according to our findings, both aspects are applied in the program, by letting employees conduct surveys and especially involving them in the development of action plans and the subsequent change process. That the line and middle managers considered the focus on employee participation as a new element in leadership training is also interesting. Not least, it says how leadership training previously has been conducted.

This particular leadership program is labeled as a health-promoting intervention. Our review of the action plans produced within the program illustrates that both healthpromoting factors and other job and workplace factors are addressed in the action plans. Of note, the health-promoting factors addressed in the action plans are rarely described as positive resources in the work environment but rather as healthy lifestyle activities. However, it is not uncommon to find discrepancies between content and labels attached to change programs (Dawson, 2003). In this case, it may have been challenging to adapt the type of resource focus to employee health that has been emphasized in more recent conceptualizations of organizational health interventions (Bauer and Jenny, 2013). The integration of health promotion and more traditional risk management has in recent 
research been put forward as an important issue for successful implementation of organizational health interventions (Karanika-Murray et al., 2012). Our review of the action plans indicates that such an integration could have been accomplished, as psychosocial work environment factors are considered in the program action plans, although these factors are often considered difficult to address.

Another aspect of implementing action plans is to have specific, realistic, and measurable goals (Karanika-Murray et al., 2012). Our findings indicate that the formulation of goals is difficult when creating the action plans. According to the managers, this might be explained by many of the employees not being used to working with 'change processes', as there are few opportunities for this in everyday work. To some extent, this also applies to the line and middle managers themselves. Including knowledge about organizational change and providing practical tools could be a possible way to overcome this barrier. Although measurement is complicated, some indicators of progress are needed. Managers had doubts about the effects and had problems identifying new work practices derived from the program; however, they also described improved dialogue and cooperation with the employees as a result of the program. It is possible as well that their limited confidence in the effects may have influenced their commitment to the program (Nytrø et al., 2000). An additional factor that is reported to facilitate implementation of organizational health interventions is the integration of solutions into regular work practice (Eriksson et al., 2010; Karanika-Murray et al., 2012). This integration aspect is described as an enabler by the managers, supporting the action plan through use of already available structures in the work environment. For example, similar action plans are created in relation to an annual employee survey.

Senior management is identified as a key stakeholder in organizational health interventions (Nielsen et al., 2010), but we found that there were line and middle managers lacking management support during implementation of the leadership program. This finding is consistent with prior studies of workplace health interventions that describe this as a major barrier during the implementation process (Mellor and Webster, 2013; Nielsen et al., 2006; Nytrø et al., 2000; Saksvik et al., 2002). In this study, there was some initial communication, support, and involvement of senior management, but this communication and support then decreased. A possible way to structure this support would be a formal steering group, but this structure would depend on available resources, and such formal support does not automatically guarantee adequate support. However, not all of the managers experienced this lack of or need for senior management support, and there may be other sources of support as well. A recent study of public sector managers' handling of workplace health shows that the managers did not turn to senior management for support or resources but instead focused on individual solutions and turned to colleagues for emotional support (Tappura et al., 2014). Another stakeholder and resource in organizational health interventions is the human resource (HR) staff within the organization. This internal capacity seems to have played a minor role in the current leadership program and represents an untapped resource in the implementation process. A recent study by Hasson et al. (2014) on the role of HR staff in organizational health interventions found that HR staff members see their role as providing both expert and hands-on support with workplace health issues. It is, therefore, conceivable that the HR staff could have assisted the participating managers with formulating goals and implementing action plans.

The process issues found in this study must also be considered in light of the organizational context. Our findings illustrate that the line and middle managers are constrained 
from participating in and implementing the program due to high workload related to job demands and broad responsibilities in their municipal operations. These differences in organizational conditions imply different positions of authority, leading potentially to variable levels of commitment to the program. It is possible that the program implementation could have benefited from a more homogeneous group of managers. As shown by a study of managerial work in municipalities, there are differences in organizational conditions for managers working in differently gendered operations (Kankkunen, 2009). Managers in municipal elderly care and educational organizations are responsible for more employees and experience less support from senior management than their counterparts in maledominated technical services. Although not a main finding in our study, this gendered pattern can also be observed in the managers involved in this leadership program.

Consistent with previous research, our findings show that the implementation of the leadership program is influenced by competing projects and other organizational changes (cf., discrete context: Biron et al., 2010; Nielsen et al., 2006; Saksvik et al., 2002). As participation in the leadership program is voluntary and it is not one of the municipality's regular projects, it seems that the program sometimes had lower priority among the line and middle managers. Although leadership is of importance for individual managers, it is not directly related to the survival of municipal operations, which may have resulted in some managers tending to be less engaged in the program. In the organizational change literature, this is referred to as perceived centrality of change, meaning the extent to which a certain change process is viewed as crucial for organizational survival (Dawson, 2003).

Finally, it is relevant to pay attention to the politics of change being involved when implementing organizational health interventions. In organizational change literature, this often refers to resistance, conflicts, and negotiation that occur between different organizational actors (Dawson, 2003). In this study, the micro-politics of change is not particularly pronounced, although there was some initial resistance to change in some work groups. It should, however, be emphasized that these findings are not based on the employees' reports. Rather, it seems that organizational politics is more influential for the line and middle managers' opportunities to engage in the implementation of the leadership program. In this context, it is an extra dimension that municipalities are 'political employers', influenced both by intra-organizational politics and by broader reforms (Bejerot and Hasselbladh, 2013). Like other public sector organizations, municipalities are influenced by market-oriented management practices stressing efficiency. New Public Management (NPM) is often used for labeling such management practices, which in this study are most clearly manifested through the competing implementation of other administrative routines and systems. Therefore, NPM-inspired practices influence the implementation of this particular leadership program indirectly by shaping working conditions for line and middle managers and contributing to a high workload. However, even more relevant is the relation between organizational health interventions and OHS regulations and policies. Recently, researchers have argued for OHS regulations as providing mandates and the potential to facilitate the implementation of organizational health interventions (Karanika-Murray et al., 2012; LaMontagne et al., 2012). However, it seems that this connection between regulations and interventions needs strengthening. Our findings indicate that this link is not clear, even though a few of the line and middle managers tried to connect program action plans with existing plans related to the work environment system. This gap between regulation and intervention 
is most likely not unique for this project, but there seem to be few prior intervention studies paying attention to it (LaMontagne et al., 2012).

\section{Relation to implementation theory}

Finally, the findings can be interpreted beyond previous research on implementation of organizational health interventions to relate to suggested theories of implementation. One such theory is Normalization Process Theory (NPT; May, 2006), which conceptualizes the process of how material practices are implemented, embedded, and integrated under complex conditions (May and Finch, 2009). Recently, the scope of the theory has been broadened from a model limited to explaining the implementation of complex interventions in health care to a middle-range theory of implementation. Although one intention of the leadership program is to reach sustainable, lasting practices and effects after the program has ended, the findings of our study show that it is difficult to talk about normalization as defined in NPT. There is significant variation in the work groups, even though steps toward making the content of the action plans routine and regular work practices are seen in some groups. Our findings can also be related to the four core components of NPT. For example, the creation of action plans is cognitive participation, in which line and middle managers legitimized and succeeded in engaging employees in the action planning process. This activity also helped position the work group for collective action to realize the implementation of the action plan. As indicated by the findings, in this action phase, the managers are challenged to mobilize resources besides everything else that is going on in the organizations. Their doubts about the potential effects of the leadership program can also be understood in terms of reflective monitoring, in which the practice is assessed by the actors involved. Another significant challenge, reflected in both interview themes, appears to have been the coherent understanding of the leadership program (i.e., practice), its implications, and the managers' opportunities to engage in the implementation process. In summary, our findings are reflected in NPT; we can view implementation as an interplay of efforts made by organizational actors (i.e., managers and employees) to improve existing practice and the dynamics of the context, including available resources for implementation.

\section{Methodological considerations}

The case study design, including the use of multiple sources of data, contributes to the understanding of barriers and enablers experienced by line and middle managers during the implementation of the leadership program. However, there are methodological aspects that must be considered when interpreting the findings of this study. The interviews were conducted after the intervention phase had been completed. Thus, the line and middle managers were interviewed once about the implementation, and they were not followed by shadowing their work practices to assess actual implementation of the program content. The managers described what they did in relation to the leadership program, but we know less about what was actually done in practice. The managers had not been informed of the intervention outcomes at the time of the interviews, which may have reduced the risk for retrospective sense making (Weick et al., 2005). The 
analysis was first conducted by the first author and then discussed and reviewed with the co-authors. These discussions may have helped to verify the analysis and the interpretations, thus contributing to the trustworthiness of the study. According to Patton (2002), the applicability of the findings can be discussed in terms of its application to other situations and similar conditions. In this study, several of the described barriers and enablers have also been pointed out in previous research, making it likely that these issues are of importance when similar workplace health interventions are implemented in comparable public sector organizations. Finally, it can be added that none of the researchers in this study was involved in the design or implementation of the investigated leadership program.

\section{Future research and practical implications}

Given our findings, future studies should focus on two issues. First, the findings illustrate that the line and middle managers experienced varying organizational conditions affecting the involvement of their employees and their ability to function as drivers of change in the organizational health interventions. Although varied conditions are described in the organizational change literature, more recent studies confirm varied working conditions among municipal managers in terms of demands, resources, and span of control (Berntson et al., 2012; Wallin et al., 2014). Intervention studies need to consider the consequences of these varied managerial work conditions for implementation of healthrelated changes. One particular issue involves the organizational conditions of managerial work at differently gendered workplaces (Björk, 2013). Second, we have tried to elucidate the political dimension involved in workplace health interventions. However, future studies need to give even greater consideration to 'organizational politics' especially as previous studies have focused mainly on the micro-level and resistance to change. The influence of other forms of interventions (e.g., nationwide political reforms) in the public sector also needs to be considered (see Bejerot and Hasselbladh, 2013). In conducting this study, we came across a broader issue related to implementation research and how to translate programs and policies into intended changes. As noted by Nilsen et al. (2013), there seems to be a limited exchange of knowledge between the research field of policy implementation research and implementation science. When investigating a program like the present one, which builds on ideas from the evidencebased practice movement, the continuing need to consider the broader political context in intervention studies is further underlined.

The practical contribution of this study is that it provides knowledge on barriers and enablers that can be incorporated into intervention planning, and considered as organizational conditions for line and middle managers in the implementation of future organizational health interventions. This knowledge can also contribute to more effective use of resources for successful implementation.

\section{Conclusion}

This study illustrates line and middle managers' experiences of the implementation of a health-promoting leadership program in municipal organizations. The leadership 
program examined is not a traditional one focusing on the individual leader but is instead characterized by employee involvement and development of the psychosocial work environment. The managers identified the following enablers: action plans with specific goals, earlier experiences of organizational change, and integration of the program content into regular routines and structures. In contrast, high workload, lack of senior management support, and inexperience with change are viewed as barriers. The findings in our study must also be considered in relation to the organizational context, including competing projects, restructuring processes, and organizational politics. In particular, the varied organizational conditions for line and middle managers need to be considered in this kind of program. Additionally, the program intensity needs to be reconsidered to strengthen the managers' commitment to the program, and support structures (e.g., HR support) need to be developed and taken into account in order to facilitate managers acting as drivers of change together with their employees.

From a theoretical perspective, it can be concluded that actors involved in the implementation of organizational health interventions ought to give more attention to the discrete context surrounding the current intervention. Although the implementation of organizational change is always subject to unexpected events, it may be worthwhile widening the perspective when planning for the implementation of complex and extensive organizational health interventions. As indicated by this study, it may be especially needed in organizations such as municipalities. The application of a processual perspective may be a way forward, not least as it involves both contextual and political aspects of change. Applying such a perspective can also help to bridge the gap that seems to exist between research on organizational health interventions and organizational change.

\section{References}

Bakker, A.B. and Demerouti, E. (2007) 'The Job Demands-Resources model: state of the art', Journal of Managerial Psychology 22(3): 309-328.

Bass, B.M. and Riggio, R.E. (2006) Transformational leadership. Mahwah, NJ: Lawrence Erlbaum Associates.

Bauer, G.F. and Jenny, G.J. (2013) From fidelity to figuration: current and emerging approaches to organizational health intervention research. In G.F. Bauer and G.J. Jenny (Eds.), Salutogenic organizations and change: the concepts behind organizational health intervention research (pp. 1-16). Dordrecht: Springer Verlag.

Bejerot, E. and Hasselbladh, H. (2013) 'Forms of intervention in public sector organizations: generic traits in public sector reforms', Organization Studies 34(9): 1357-1380.

Berntson, E., Wallin, L. and Härenstam, A. (2012) 'Typical situations for managers in the Swedish public sector: cluster analysis of working conditions using the Job Demands-Resources model', International Public Management Journal 15(1): 100-130.

Biron, C., Gatrell, C. and Cooper, C.L. (2010) 'Autopsy of a failure: evaluating process and contextual issues in an organizational-level work stress intervention', International Journal of Stress Management 17(2): 135-158.

Biron, C., Karanika-Murray, M. and Cooper, C.L. (2012) Organizational interventions for stress and well-being - an overview. In C. Biron, M. Karanika-Murray and C.L. Cooper (Eds.), Improving organizational interventions for stress and well-being: addressing process and context (pp.1-17). London: Routledge.

Björk, L. (2013) Contextualizing managerial work in local government organizations. Gothenburg: University of Gothenburg. 
Bowen, G.A. (2009) 'Document analysis as a qualitative research method', Qualitative Research Journal 9(2): 27-40.

Braun, V. and Clarke, V. (2006) 'Using thematic analysis in psychology', Qualitative Research in Psychology 3(2): 77-101.

Burke, W.W. (2011) Organization change: theory and practice. Thousand Oaks, CA: Sage Publications.

Caldwell, R. (2005) 'Things fall apart? Discourses on agency and change in organizations', Human Relations 58(1): 83-114.

Chu, C., Breucker, G., Harris, N., Stitzel, A., Gan, X., Gu, X. and Dwyer, S. (2000) 'Health-promoting workplaces - international settings development', Health Promotion International 15(2): 155-167.

Cox, T., Karanika, M., Griffiths, A. and Houdmont, J. (2007) 'Evaluating organizationallevel work stress interventions: beyond traditional methods', Work \& Stress 21(4): 348-362.

Dawson, P. (2003) Understanding organizational change: the contemporary experience of people at work. London: Sage Publications.

Egan, M., Bambra, C., Petticrew, M. and Whitehead, M. (2009) 'Reviewing evidence on complex social interventions: appraising implementation in systematic reviews of the health effects of organizational-level workplace interventions', Journal of Epidemiology and Community Health 63(1): 4-11.

Eriksson, A. (2011) Health-promoting leadership: a study of the concept and critical conditions for implementation and evaluation. Gothenburg: The Nordic School of Public Health.

Eriksson, A., Axelsson, R. and Axelsson, S.B. (2010) 'Development of health-promoting leadership - experiences of a training program', Health Education 110(2): 109-124.

European Network for Workplace Health Promotion. (2007) The Luxembourg declaration on workplace health promotion in the European Union. Luxembourg.

Goldgruber, J. and Ahrens, D. (2010) 'Effectiveness of workplace health promotion and primary prevention interventions: a review', Journal of Public Health 18(1): 75-88.

Härenstam, A., Marklund, S., Berntson, E., Bolin, M. and Ylander, J. (2006) Understanding the organizational impact on working conditions and health. Stockholm: Arbetslivsinstitutet.

Hasenfeld, Y. (2010) Human services as complex organizations. Los Angeles, CA: Sage Publications.

Hasson, H., Villaume, K., von Thiele Schwarz, U. and Palm, K. (2014) 'Managing implementation: roles of line managers, senior managers, and human resource professionals in an occupational health intervention', Journal of Occupational and Environmental Medicine 56(1): 58-65.

Inauen, A., Jenny, G.J. and Bauer, G.F. (2012) 'Design principles for data- and change-oriented organizational analysis in workplace health promotion', Health Promotion International 27(2): 275-283.

Johns, G. (2006) 'The essential impact of context on organizational behavior', Academy of Management Review 31(2): 386-408.

Kankkunen, T. (2009) Två kommunala rum: ledningsarbete i genusmärkta tekniska respektive omsorgs- och utbildningsverksambeter (Two municipal rooms: managerial work in gendered technical as well as social care and educational operations). Stockholm: Stockholms universitet.

Karanika-Murray, M. and Biron, C. (2013) The nature of change in organizational health interventions: some observations and propositions. In G.F. Bauer and G.J. Jenny (Eds.), Salutogenic organizations and change: the concepts behind organizational health intervention research (pp. 239-258). Dordrecht: Springer Verlag. 
Karanika-Murray, M., Biron, C. and Cooper, C.L. (2012) Concluding comments: distilling the elements of successful organizational intervention implementation. In C. Biron, M. Karanika-Murray and C.L. Cooper (Eds.), Improving organizational interventions for stress and well-being: addressing process and context (pp. 353-361). London: Routledge.

Kelloway, E.K. and Barling, J. (2010) 'Leadership development as an intervention in occupational health psychology', Work \& Stress 24(3): 260-279.

Kvale, S. and Brinkmann, S. (2009) Interviews: learning the craft of qualitative research interviewing. Thousand Oaks, CA: Sage Publications.

LaMontagne, A.D., Keegel, T., Louie, A., Ostry, A. and Landsbergis, P.A. (2007) 'A systematic review of the job-stress intervention evaluation literature, 1990-2005', International Journal of Occupational Environmental Health 13(3): 268-280.

LaMontagne, A.D., Noblet, A.J. and Landsbergis, P.A. (2012) Intervention development and implementation: understanding and addressing barriers to organizational-level interventions. In C. Biron, M. Karanika-Murray and C.L. Cooper (Eds.), Improving organizational interventions for stress and well-being: addressing process and context (pp. 21-38). London: Routledge.

Lewin, K. (1951) Field theory in social science: selected theoretical papers. D. Cartwright (Ed.). New York, NY: Harper \& Row.

Lindgren, H. (2014) Processtudien - en studie av Chefios-interventionens förändringsprocesser (The process study - a study of the Chefios-intervention's change processes). I A. Härenstam, \& A. Östebo (Red.), Förändringsprocesser och utvärderingar av interventioner $i$ kommunala förvaltningar: Metoder och resultat frän CHEFiOS projektet - slutrapport del 2 (Change processes and evaluations of interventions in local government departments: Methods and results from the CHEFiOS project - Final report part 2) (s. 37-99). Göteborg: Institutet för stressmedicin.

Linnan, L. and Steckler, A. (2002) Process evaluation for public health interventions and research: an overview. In A. Steckler and L. Linnan (Eds.), Process evaluation for public health intervention and research (pp. 1-23). San Francisco, CA: Jossey-Bass.

May, C. (2006) 'A rational model assessing and evaluating complex interventions in health care', BMC Health Service Research 6: 86.

May, C. and Finch, T. (2009) 'Implementing, embedding, and integrating practices: an outline of normalization process theory', Sociology 43(3): 535-554.

Mellor, N. and Webster, J. (2013) 'Enablers and challenges in implementing a comprehensive workplace health and well-being approach', International Journal of Workplace Health Management 6(2): 129-142.

Montano, D., Hoven, H. and Siegrist, J. (2014) 'Effects of organizational-level interventions at work on employees' health: a systematic review', BMC Public Health 14: 135.

Murta, S.G., Sanderson, K. and Oldenburg, B. (2007) 'Process evaluation in occupational stress management programs: a systematic review', American Journal of Health Promotion 21(4): 248-254.

Nielsen, K. (2013) 'Review article: How can we make organizational interventions work? Employees and line managers as actively crafting interventions', Human Relations 66(8): 1029-1050.

Nielsen, K. and Abildgaard, J.S. (2013) 'Organizational interventions: a research-based framework for the evaluation of both process and effects', Work \& Stress 27(3): 278-297.

Nielsen, K., Fredslund, H., Christensen, K.B. and Albertsen, K. (2006) 'Success or failure? Interpreting and understanding the impact of interventions in four similar worksites', Work \& Stress 20(3): 272-287.

Nielsen, K. and Randell, R. (2013) 'Opening the black box: presenting a model for evaluating organizational-level interventions', European Journal of Work and Organizational Psychology 22(5): 601-617. 
Nielsen, K., Randall, R., Holten, A.-L. and Rial González, E. (2010) 'Conducting organizational-level occupational health interventions: what works?', Work \& Stress 24(3): 234-259.

Nilsen, P., Ståhl, C., Roback, K. and Cairney, P. (2013) 'Never the twain shall meet? - a comparison of implementation science and policy implementation research', Implementation Science 8: 63.

Nytrø, K., Saksvik, P. Ø., Mikkelsen, A., Bohle, P. and Quinlan, M. (2000) 'An appraisal of key factors in the implementation of occupational stress interventions', Work \& Stress 14(3): 213-225.

O’Donnell, M.P. (Ed.) (2002) Health promotion in the workplace. Albany, NY: Delmar Thomson Learning.

Patton, M.Q. (2002) Qualitative research \& evaluation methods. Thousand Oaks, CA: Sage Publications.

Pettigrew, A.M. (1997) 'What is a processual analysis?', Scandinavian Journal of Management, 13(4): 337-348.

Rigotti, T., Holstad, T., Mohr, G., Stempel, C., Hansen, E., Loeb, C., Isaksson, K., Otto, K., Kinnunen, U. and Perko, K. (2014) Rewarding and sustainable health-promoting leadership. Dortmund/Berlin/Dresden: Federal Institute for Occupational Safety and Health.

Saksvik, P. Ø., Nytrø, K., Dahl-Jørgensen, C. and Mikkelsen, A. (2002) 'A process evaluation of individual and organizational occupational stress and health interventions', Work \& Stress 16(1): 37-57.

Shain, M. and Kramer, D.M. (2004) 'Health promotion in the workplace: framing the concept; reviewing the evidence', Occupational and Environmental Medicine 61(7): 643-648.

Sockoll, I., Kramer, I. and Bödeker, W. (2009) Effectiveness and economic benefits of workplace health promotion and prevention: summary of the scientific evidence 2000 to 2006. IGA - Initiative Gesundheit \& Arbeit. [online 10.11.2014]. Available: http://www.iga-info.de/fileadmin/Veroeffentlichungen/iga-Reporte_Projektberichte/iga-Report_13e_effectiveness_workplace_prevention.pdf

Stokols, D., Pelletier, K.R. and Fielding, J.E. (1996) 'The ecology of work and health: research and policy directions for the promotion of employee health', Health Education and Behavior 23(2): 137-158.

Tappura, S., Syvänen, S. and Saarela, K.L. (2014) 'Challenges and needs for support in managing occupational health and safety from managers' viewpoints', Nordic Journal of Working Life Studies 4(3): 31-51.

Tetrick, L.E., Quick, J.C. and Gilmore, P.L. (2012) Research in organizational interventions to improve well-being: perspectives on organizational change and development. In C. Biron, M. Karanika-Murray and C.L. Cooper (Eds.), Improving organizational interventions for stress and well-being: addressing process and context (pp. 59-76). London: Routledge.

Wallin, L., Pousette, A. and Dellve, L. (2014) 'Span of control and the significance for public sector managers' job demands: a multilevel study', Economic and Industrial Democracy 35(3): 455-481.

Weick, K.E., Sufcliffe, K.M. and Obstfeld, D. (2005) 'Organizing and the process of sensemaking', Organization Science 16(4): 409-421.

Weiner, B.J., Lewis, M.A. and Linnan, L.A. (2009) 'Using organization theory to understand the determinants of effective implementation of worksite health promotion programs', Health Education Research, 24(2): 292-305.

World Health Organization. (1986) Ottawa charter for health promotion. Geneva: WHO.

Yin, R.K. (2009) Case study research: design and methods. Thousand Oaks, CA: Sage Publications.

Yukl, G.A. (2006) Leadership in organizations. Upper Saddle River, NJ: Prentice Hall. 